Background The Finnish Transport Agency is an expert organisation responsible for Finland's roads, railways and waterways and for the overall development of Finland's transport system. FTA operates under the jurisdiction of the Ministry of Transport and Communications. It is FTA's responsibility to maintain the high quality of Finnish infrastructure, which in its turn enables mobility services, robotization and digitalization.

Infra Contractors Association's main mission is to improve their member companies' business. Member companies build and maintain roads, streets, railways, waterways, harbours and airports, parks and sports grounds, pipelines, sewer networks, power-distribution networks, telecommunications network and produce aggregates that are vital for all construction.

Methods The Finnish Transport Agency and Infra Contractors Association work constantly together to improve occupational safety at the infra worksites. The target is to improve occupational safety (norms, instructions and procedures) and the safety management. Both, The Finnish Transport Agency and Infra Contractors Association have different safety competitions and campaigns, which are supporting each other.

Results The newest joint venture is the "Rail Road Forum". Its aim is to gather together all who somehow operates in the rail road. The main focus is to develop rail road from different aspects in open co-operation, together. And off course one important sub-group is Safety and Security Group.

This is only one prove of success of what doing together can make.

Conclusions Through the constant cooperation amongst with all the parties it is possible to gain better safety of work.

\section{PHYSICAL WORKLOAD OF SEAFARERS DURING EMERGENCY EXERCISE COURSE}

Päivi Miilunpalo, Susanna Visuri, Harri Lindholm, Sirpa Lusa, Mia Pylkkonen. Finnish Institute of Occupational Health, Finland

\subsection{6/injuryprev-2016-042156.995}

Background Every seafarer must be able to perform both, normal duties and emergency situations on board ship. There are few studies of the physical demands of emergency duties on board ship. The aim of the study was to measure the physical strain during emergency training drill (basic safety training BST), which is mandatory for every seafarer. Some of the maritime emergency tasks (like smoke diving) are much heavier than the emergency duties in basic safety training. Therefore BST tasks form the minimum strain level every seafarer has to perform.

Methods Eighteen firefighting male seafarers and five other female seafarers aged 24-45 were recruited to study. They all attended to physical examination and to fitness tests. Ability to perform 100 metre's swimming in rough sea, climbing ladders up, turning an upturned life raft, and climbing to a life raft from water were tested in a maritime safety training centre. Physical strain of these tasks was assessed by heart rate variability method and by Borg Rating of Perceived Exertion Scale.

Results Results of the heart rate variability show that even in good physical shape the tasks tested are causing strain and load peaks. Swimming was causing the highest strain; the physical load among males was 7.9 (4-11) MET and perceived exertion was $12(8-14)$. Climbing ladders up caused the lowest strain 6 (3-9) MET. The average physical load of climbing to a life raft was $7 \mathrm{MET}$ and turning of an upturned life raft was about at the same level. On average, the women strained more than the males.

Conclusions The tasks in simulated rescue training cause short term aerobic strain in controlled environment. In real life settings the emergency tasks are more demanding. Poor aerobic fitness is a risk factor for exhaustion and accidents during emergency situations. This is not only a risk for the safety of the vessel and other crew but it also puts seafarer's own life in danger in emergency situations. Based on these results even the safe rescue training requires at least normal performance capacity. It is however highly important to support the physical rehabilitation and exercise training of the seafarers with decreased fitness, because the appropriate rescue training improves skills and reduces strain. The functional resources to manage rescue activities should be included in health examinations.

\section{THE DIFFERENCE OF FEMALE LABOUR'S WORK FATIGUE LEVEL BETWEEN THE MORNING, EVENING, AND NIGHT SHIFTS IN WINDING PT. ISKANDAR INDAH PRINTING TEXTILE SURAKARTA}

Eka Rosanti. University of Darussalam Gontor, Ponorogo

\subsection{6/injuryprev-2016-042156.996}

Background This research was aimed to know and investigate the difference of female labour's work fatigue level between the morning, evening, and night shifts in winding PT. Iskandar Indah Printing Textile Surakarta.

Methods This research is an observational cross sectional analytical approach, sample were 56 woman in Winding division. Sampling technique uses in this research was purposive sampling by determining the predefined characteristics. The data collection was done by measuring the labour fatigue level using Reaction Timer. The data analysis used statistic non parametric kruskal Wallis by using computer program SPSS 17.00 Version.

Results The result of statistic showed the difference of female labour's work fatigue level between the morning $(326,41 \pm 79,52)$, evening $(393,32 \pm 83,20)$, and nights shift $(483,00 \pm 118,66)$ showed very significance value $\mathrm{p}=0.001$.

Conclusions The highest level of fatigue was night shift. To solved this problems, it could be recommended by giving some nutritions, providing shuttle facilities for female night shift workers and applying rotation shift patern with rota metropolitan (22 ) and rota continental (2-3). Design recommendations: as few night shifts as possible, no more than two to four consecutive night shifts, forward rotation: early-late-night, avoidance of the accumulation of working hours, as far as possible two consecutive days off at the weekend, early shift not to start too early, night shift not to end too late, and predictability of shift schedule.

\section{KNOWLEDGE AND PRACTICE OF INJECTION SAFETY AMONG SURGICAL NURSES IN POLAND: AN INTERVENTION STUDY}

${ }^{1}$ Maria Ganczak, ${ }^{2}$ Adam Szczeniowski, 'Zbigniew Szych. ${ }^{1}$ Pomeranian Medical University in Szczecin, Poland; ${ }^{2}$ Provincial Hospital in Jawor, Poland

\subsection{6/injuryprev-2016-042156.997}

Background Medical staff members are exposed to the risk of sharps injuries, which may result in contracting blood-borne infections. The objective of this quasi-experimental pre-test/post- 
test research study was to examine the effectiveness of an intervention designed through a participatory process to improve knowledge and safe work practices, as well as to reduce sharps injuries among nurses.

Methods The study population was surgical nurses from 16 randomly selected hospitals in north-western Poland. Data were collected between 2009-2011 with the use of self-administered, ano-nymous pre-intervention/post-intervention questionnaires containing records of demographic cha-racteristics, self-reported sharps injuries, knowledge (12 items) and practices on injection safety, before/ 1 year after the educational intervention which included a 2 hour lecture.

Results Of 91 participants (mean age 42.8, range 24-59 years) for whom the pre-intervention and post-intervention questionnaires could be directly matched, 20.9\% worked at teaching, $15.4 \%$ - at other urban, $63.7 \%$ - at provincial hospitals; $64.8 \%$ were employed at surgical, $24.2 \%$ - at gynaecological wards, $11.0 \%$ - in the admitting area. The mean level of knowledge on injection safety before the intervention was 3.09, it increased to 4.12 after $(\mathrm{p}<0.001)$, including the improvement of the knowledge of the post-exposure prophylaxis $(p<0.001)$. Before the intervention $48.4 \%$ of respondents had had a needle-stick injury in the previous year, the number decreased (20.9\%) after the intervention, $\mathrm{p}<0.001$; before intervention $47.5 \%$ reported recapping needles after use, and 30.0\% - after, $\mathrm{p}<0.05$.

Conclusions Despite a high risk of contracting a blood-borne infection due to unsafe practices at work and numerous sharps injuries, surgical nurses had alarmingly low knowledge on injection safety. Educational intervention can have a long-term positive impact on the improvement of knowledge and safe work practices and reduce sharps injuries.

\section{FARMERS' OCCUPATIONAL ACCIDENTS IN FINLAND}

Jukka Mäittälä, Merja Perkiö-Mäkelä, Maria Hirvonen, Birgitta Kinnunen, Milja Koponen, Kyösti Louhelainen, Jouni Sipponen. Finnish Institute of Occupational Health, Kuopio, Finland

\subsection{6/injuryprev-2016-042156.998}

Background According to the statistics of the Farmers' Social Insurance Institution Mela, approximately six per cent of insured farmers have received compensation for an occupational accident in recent years.

Methods The study population consisted of 3117 farmers and was weighted to be equivalent to the actual distribution of the production sector in Finland in 2014. The data was collected through computer-assisted telephone interviews (CATI). The structure of the interviews was planned by a group of experts at the Finnish Institute of Occupational Health, and included questions on the nature of occupational accidents.

Results Of the interviewed farmers, $15 \%$ had had an accident during farm work in the previous 12 months. Out of these, two thirds required medical care after the accident. Livestock farmers were far more likely to have had occupational accidents than crop farmers. One in four (25\%) dairy cattle farmers had had an accident, while the number for crop farmers was $11 \%$. Relative to part-time farmers, full-time farmers had had more accidents (19\% and 7\%, respectively) and were also more likely to have required medical care afterwards (13\% and 5\%, respectively). The most recent occupational accident for which farmers had seen a doctor had usually occurred either during cattle tending (24\%), forest work (13\%) or maintaining machines (12\%).
Conclusions According to the farmers' own accounts, there had been a third more occupational accidents requiring medical care than what is shown in the compensation statistics of Mela. This is largely explained by the bonus system of the current farmer's accident insurance legislation in which the insurance fees significantly decrease after a number of years without accidents. The greater frequency of accidents among full-time farmers is explained both by a greater amount of time spent on farm work and a larger focus on the more high-risk livestock farming.

\section{NEW APPROACH ABOUT ACCIDENT PREVENTION}

Piia Mattila. Ministry of Social Affairs and Health, Department for Occupational Safety and Health, Finland

\subsection{6/injuryprev-2016-042156.999}

Background Department for Occupational Safety and Health of the Ministry of Social Affairs and Health ordered a preliminary study on a topic called "modern accident program" which means a new approach to accident prevention. The basis for this program was the strategy for social and health policy Socially Sustainable Finland 2020 and the document Policies for the work environment and well-being at work until 2020. This study was completed in end of the year 2014 and it was carried out by VTT (Technical Research Centre of Finland) in cooperation with Tampere University of Technology (TTY).

Description of the problem One goal of the Policies for the work environment and well-being at work until 2020 (compared to the year 2010) is to reduce the frequency of workplace accidents by $25 \%$. The frequency hasn't reduced as we hope to. In Finland, we need new tools for accident prevention.

Results The targets of this program correspond to the recommended actions of the preliminary study. The program is not carried out elsewhere as a separate program. It's a new approach that promotes best practices in accident prevention and cooperation among stakeholders.

Conclusions The target year of these goals is 2025. It's the same target year as for the future review Working life 2025 which has been written in the Department for Occupational Safety and Health of the Ministry of Social Affairs and Health.

\section{PSYCHOSOCIAL/PSYCHOSOMATIC CONSEQUENCES ON EMPLOYEES IN LOCAL GOVERNMENT ADMINISTRATION OF TWO MUNICIPALITIES IN THE CITY OF ATHENS, AFTER THE IMPLEMENTATION OF THE "KALLIKRATES PLAN" PROGRAM IN THE COUNTRY}

'Georgia S Tzamaloukas, ${ }^{2}$ Kate Koliopoulou, ${ }^{3}$ Elena Riza, ${ }^{3}$ Athena Linos. 1 Senior Researcher, Social Psychologist, in Laboratory of Health and Road Safety. of TEl/Crete- Greece, ; 2Social Worker, Municipality of Keratsini/Drapetsona-Athens; ${ }^{3}$ Department of Hygiene, Epidemiology and Medical Statistics-Medical School - National and Kapodistrian University of Athens

\subsection{6/injuryprev-2016-042156.1000}

Background Reconstruction and/or merging of Greek Businesses and Services, by a program which is called "Kallikrates", ("Kallikrates Plan" is a major administrative reform in Greece, aiming to the restructuration and better administrative cooperation among the thirteen regions of Greece).This reform plan has direct and indirect consequences on employees' health condition and security in Local Government Administration (L.G.A) work places. Staff reduction, new responsibilities, work overload, unexpected horizontal staff transfers, roles ambiguity, and job insecurity, 